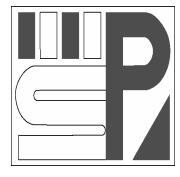

Science Press
Journal of Arid Land

2012, 4(2): 113-122

doi: 10.3724/SP.J.1227.2012.00113

jal.xjegi.com; www.chinasciencejournal.com

\title{
Periodical characteristics of baseflow in the source region of the Yangtze River
}

\author{
KaiZhu QIAN*, Li WAN, XuSheng WANG, JingJing LV, SiHai LIANG \\ School of Water Resources and Environment, China University of Geosciences (Beijing), Beijing 100083, China
}

\begin{abstract}
Baseflow, which represents the drainage of groundwater aquifers, is an essential component of runoff in hydrological basins. In the source region of the Yangtze River, the change of baseflow typically reflects the interactions between groundwater system and climatic factors in cold and arid areas. With modified Kalinen separation method, annual baseflow between 1957 and 2009 in this region was estimated and calculated. In comparison with the inner-annual variations of total streamflow, baseflow showed a weaker fluctuation. Before the 1980s, it was in a steady state; and after then, it demonstrated dramatic variations and large amplitudes. Based on the calculation results of baseflow, the real Morlet wavelet method was applied to reveal the periodical characteristics of baseflow as well as the precipitation and air temperature in the study area. It was found that annual baseflow has a 43-year trend as well as a 21-year period and a 7-year period. The 21-year period is most significant, with its wavelet coefficient having the largest fluctuation and amplitude. Summation of wavelet coefficients on these periods exhibits a similar change pattern with respect to that of annual baseflow. The summation curve takes a "W" shape, which means that the baseflow follows a four-stage sequence of descending-ascending-descending-ascending. As analyzed, the relationship among baseflow, precipitation and temperature is implied in the correlation between their normalized wavelet coefficients at different temporal scales. By the significant positive linear correlations both between precipitation and baseflow (correlation coefficient is 0.98 ) and between temperature and baseflow (correlation coefficient is 0.90 ) for the 43-year wavelet coefficients, it is suggested that the long-term increasing trends of precipitation and air temperature will lead to an increasing trend of baseflow. For wavelet coefficients of 21 -year and 7 -year periods, the positive linear correlation between precipitation and baseflow is significant. However, the correlation between air temperature and baseflow is not so evident, especially for the 21-year period. As a conclusion, correlation analysis with normalized wavelet coefficients showed that the change of annual baseflow was contributed mostly by the change of precipitation and secondly by the change of temperature.
\end{abstract}

Keywords: baseflow; climate; Kalinen separation method; Morlet wavelet; Yangtze River

The source region of the Yangtze River is in the central area of the Qinghai-Tibet Plateau. This region is one of the typical areas for investigation of interactions among hydrology, ecology and meteorology. In recent years, under global climate changes, the shrinkage of lakes and wetlands, the degradation of meadows and the melting of permanent frozen soils have threaten the whole plateau and the Yangtze River Basin (Kang et al., 1999; Wang and Chen, 2001; Chen et al., 2002; Lu et al., 2005; Yang et al., 2007; Zhang and Gao, 2007). These problems give rise to concerns on the source region of the Yangtze River from inter- national society and academia.

The change of runoff in river basins at regional scales is regarded as an indicator of local eco-hydrological response to global climate change. As the subsurface component of runoff, baseflow has a unique importance in the studies of seasonal and annual flow patterns and ecological water demand in river basins (Tallaksen, 1995; Yin et al., 2004; Huang and Chen, 2005; Liu et al., 2005; Chen et al., 2006a; Aksoy et al., 2008, 2009; Aksoy and Wittenberg, 2010), and can

Received 2011-09-30; accepted 2012-02-06

*Corresponding author: KaiZhu QIAN (E-mail: qiankaizhu@126.com) 
be complicatedly influenced by geological conditions, precipitation, temperature and landuse (Vogel and Kroll, 1992; Wittenberg, 1999, 2003; Wittenberg and Sivapalan, 1999; Zhang and Schilling, 2006; Aksoy and Wittenberg, 2011). As an example, it was found that the reduction of baseflow in the source region of the Yellow River is a composite result of climate conditions and human activities at multi-time scales, which can not be simply explained by linear trends of precipitation and air temperature (Chen et al., 2006b; Liang et al., 2007; Liang et al., 2008). The relationship between runoff and climate in the source region of the Yellow River is typically implied in the periodical characteristics of streamflow, precipitation and air temperature (Liang et al., 2010). The baseflow in the source region of the Yangtze River, that in the Tongtianhe River in particular, has not yet been well investigated. This region is cold and arid. Permanent and seasonal frozen soils are developed in the region and their thickness is largely determined by air temperature. Since precipitation and frozen soils play an essential role in groundwater flow, it can be expected that the baseflow of the Tongtianhe River is subject to both precipitation and air temperature.

In this study, with relevant hydrological data for the source region of the Yangtze River, the long-term baseflow of the Tongtianhe River was abstracted by Kalinen separation method. Then the periodical characteristics of the baseflow were analyzed by Morlet wavelet method. The impacts of precipitation and air temperature on baseflow were investigated, as well to discuss the trend of change.

\section{Study area}

The source region of the Yangtze River is located in the central part of the Qinghai-Tibet Plateau with a catchment area of $158,500 \mathrm{~km}^{2}$, falling within $32^{\circ} 26^{\prime}-35^{\circ} 46^{\prime} \mathrm{N}$ and $90^{\circ} 33^{\prime}-95^{\circ} 20^{\prime} \mathrm{E}$ (Fig. 1). The main stream in the region is the Tongtianhe River, which is one of the upstream branches of the Yangtze River. The Tuotuohe River and Chumaer River are two relatively large branch rivers in the upstream area of the Tongtianhe River. The river basin is bounded by the Tanggula Mountains and Kunlun Mountains. The regional altitude ranges from more than $6,000 \mathrm{~m}$ in the west to lower than $4,000 \mathrm{~m}$ in the east, but is generally

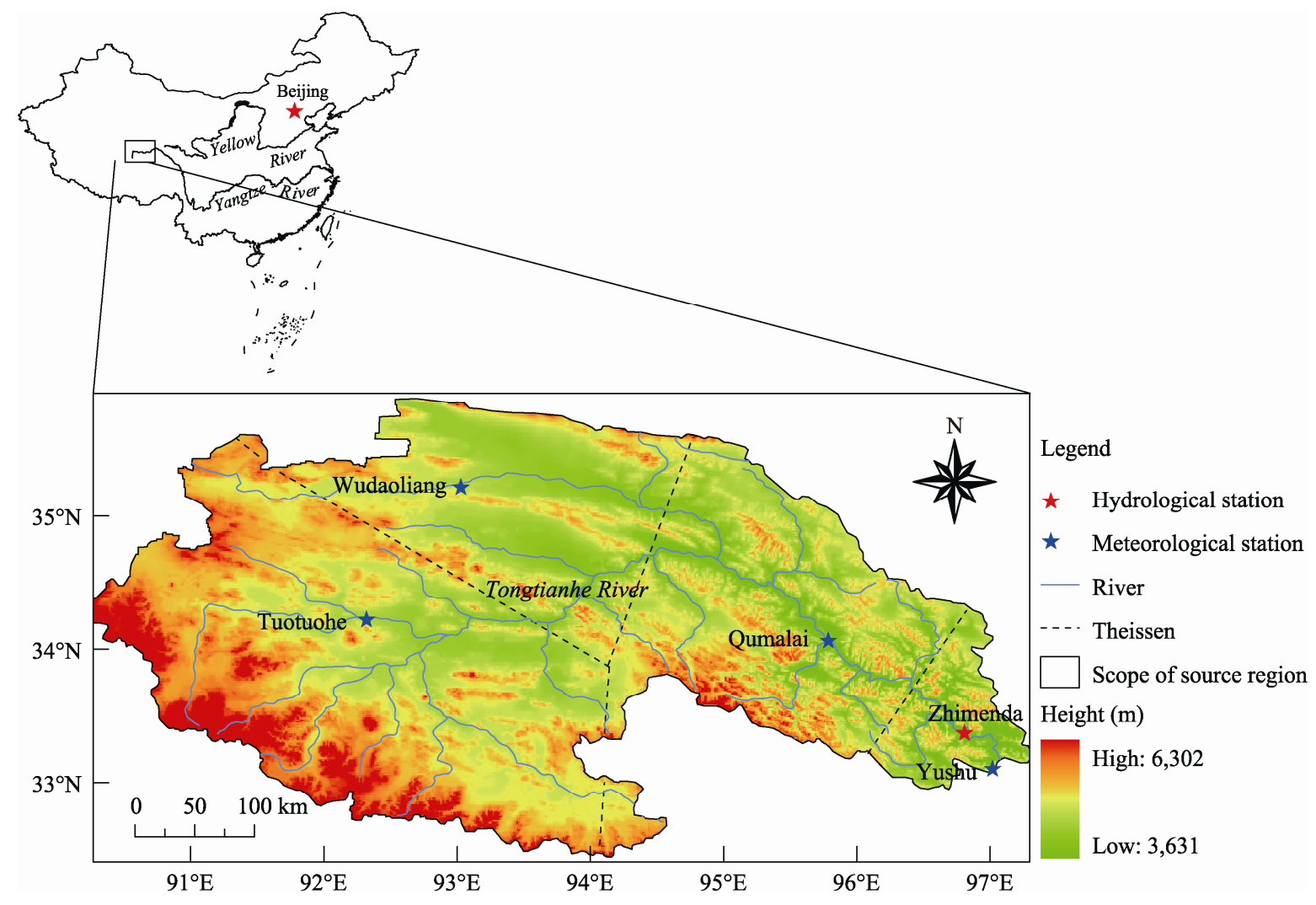

Fig. 1 The source region of the Yangtze River 
higher than 3,600 $\mathrm{m}$. The mean annual air temperature is about $-4.2^{\circ} \mathrm{C}$, and the mean annual precipitation approximates $354 \mathrm{~mm}$. Total precipitation is mainly contributed by rainfall in the summer but snow, sleet and hail in the other seasons also play an important role in contribution to annual precipitation. On average, the annual relative humidity ranges between $55 \%$ and $60 \%$, and the annual potential evaporation is about $1,317 \mathrm{~mm}$ (Hu et al., 2009).

The metrological data in this region are obtained from four meteorological stations called Tuotuohe station, Qumalai station, Yushu station and Wudaoliang station (Fig. 1). Near the east boundary, a hydrological station, Zhimenda station, is located close to the meteorological station at Yushu. Meteorological and hydrological data from 1957-2009 are available at the stations. The hydrological station is in the outlet of the source region, so that the runoff of the Tongtianhe River can be observed. And the rivers (Tuotuohe River, Chumaer River, etc.) converge into Tongtianhe River at the outlet and then discharge out of the region. Thus, the observed data can reflect the change of runoff in the whole source region of the Yangtze River.

\section{Methods}

\subsection{Development of baseflow separation method}

According to hydro-geological conditions and baseflow processing of different catchments, various methods have been raised by researchers. They can be classified into such methods as graphic analysis, numerical simulation, hydrological modeling, physical chemistry and mathematical physics. The experience-based graphic analysis method is to separate hydrograph geometrically, including linear horizontal separation and linear slant separation. By consideration of simplicity and subjectivity of the graphical approach, and combining with computer technology and signal processing, the numerical simulation method was raised, which mainly includes filtering and Kalinen separation. However, the hydrological meaning of parameters for this method is not explicit, as it has not been confirmed completely. The hydrological modeling method is to apply hydrological circulation to calculate each part of water balance. With the development of isotope monitoring technology, physical chemistry method is introduced to use isotope tracer to calculate the ratio of baseflow in runoff. Because of the strict requirements of monitoring instruments and regional hydrological conditions, it has not yet been applied widely. All the above methods have not been quite used as solutions to the baseflow production mechanism. Thus based on formula derivation and mechanism model establishment, the mathematical physics method is widely studied, the representative of which is the hydrodynamic approach (Qian et al., 2011a).

\subsection{Modified Kalinen baseflow separation method}

The feature of flood recession curve has a close relationship with the basin water conservation characteristics in a watershed and has been applied in the analysis of baseflow. Generally, the decaying of the flood $(Q)$ has an exponential relationship with elapse time step $(t)$, as follows:

$$
Q(t)=Q_{0} \exp (-\alpha t)
$$

Where, $Q_{0}$ is the initial flow rate for the break point at the beginning of recession; $\alpha$ is the recession index which reflects the release of subsurface runoff. The recession index can be estimated through a logarithm linear diagram of recession curve if the break point is appropriately chosen.

The ratio of subsurface runoff to surface runoff, $B$ is another essential parameter in baseflow separation analysis defined as:

$$
\begin{gathered}
B=\frac{Q_{\text {sub }}}{Q_{\text {sur }}}, \\
Q_{\text {sur }}=Q_{\text {total }}-Q_{\text {sub }} .
\end{gathered}
$$

Where, $Q_{\text {sub }}$ and $Q_{\text {sur }}$ represent subsurface runoff and surface runoff, respectively; $Q_{\text {total }}$ is total runoff. The determination of the ratio involves a test process to ensure that the baseflow is always not larger than the observed total runoff.

In estimating variable subsurface runoff, Kalinen (Jin, 1982) suggested an equation as follows:

$$
\begin{aligned}
Q_{s u b, t} & =Q_{s u b, t-1}+B \alpha Q_{s u r, t-1} \Delta t-(1+B) \alpha Q_{s u b, t-1} \Delta t \\
& =B \alpha Q_{s u r, t-1} \Delta t+(1-((1+B) \alpha \Delta t)) Q_{s u b, t-1} .
\end{aligned}
$$

Where $Q_{s u b, t}$ and $Q_{s u b, t-1}$ are subsurface runoff at discrete time (time step) $t$ and $t-1$, respectively. This method was improved by considering a lumped effect of previous runoff on present runoff (Zhang, 1985), as given by: 


$$
Q_{s u b, t}=\theta\left[\begin{array}{l}
Q_{s u r, t-1}+\lambda Q_{s u r, t-2}+ \\
\lambda^{2} Q_{s u r, t-3}+\cdots+\lambda^{t-2} Q_{s u r, 1}
\end{array}\right]+\lambda^{t-1} Q_{s u b, 1} .
$$

Where $\theta=B \alpha \Delta t$ and $\lambda=1-(1+B) \alpha \Delta t$. Furthermore, the equation was simplified by Chen et al. (2006c) as follows:

$$
Q_{\text {sub }, t}=\theta Q_{\text {sur }, t-1}+\lambda Q_{\text {sub }, t-1} .
$$

Where $\theta$ and $\lambda$ have the same representation as in Eq. 5. This modified Kalinen separation method has shown its efficiency in practice (Chen et al., 2006c). The determination of the two unknown parameters, $\alpha$ and $B$, is based on the analysis of monthly runoff data and results in variable parameter values that have been reported by Qian et al. (2011b). In addition, the advanced Kalinen baseflow separation method is used well in catchments little influenced by human activities, such as the source region of the Yangtze River (Chen et al., 2006b, c; Liang et al., 2007; Liang et al., 2008; Qian et al., 2011b). Thus, the annual baseflow taken for analysis in this study is derived from monthly data.

\subsection{Wavelet method}

Wavelet method is a powerful method in analyzing time signal series at different periodical and frequency domains. It has been widely applied in the community of geosciences (Grossman and Morlet, 1984; Guyodo et al., 2000). In particular, it is efficient for the analysis of long-term time series such as temperature, precipitation, humidity, and extreme climatic phenomena including ENSO (El Niño Southern Oscillation), SOI (Southern Oscillation Index) and NAO (North Atlantic Oscillation) (Compagnucci et al., 2000; Labat, 2005). The periods or frequencies of streamflow have also been studied by wavelet transformation (Coulibaly and Burn, 2004; Labat et al., 2005; Adamowski and Sun, 2010; Kisi, 2010). In comparison with Fourier analysis, wavelet transformation is more effective in providing fine time resolutions for long duration signals and fine frequency resolutions for high frequency signals (Bayazit and Aksoy, 2001; Hsu, 2010). Wavelet method is, therefore, a better choice in the study of multi-scale and non-stationary properties of precipitation, temperature and baseflow over finite spatial and temporal domains. Thus, to reveal the periodical characteristics of baseflow in this study area and analyze the relationship between runoff, precipitation and air tem- perature, wavelet method was used.

On the basis of a time series or a continuous function, $f(t)$, the time-scale coefficient $C(a, \tau)$ is derived by wavelet transformation, being defined as follows (Labat, 2008):

$$
C(a, \tau)=\frac{1}{\sqrt{a}} \int_{-\infty}^{\infty} f(t) \psi^{*}\left(\frac{t-\tau}{a}\right) d t .
$$

Where, $\psi^{*}$ is the complex conjugate of the wavelet function $\psi$, which can be real or not; $a$ and $\tau$ are the scale and shift time, respectively; $C(a, \tau)$ represents the conditional correlation between the wavelet function $\psi$ and time signal series $f(t)$. The parameters $a$ and $\tau$ are used to change the location and shape of $\psi$.

The wavelet transformation can be operated with different types of wavelet function $\psi$, such as the Morlet wavelet, the Haar wavelet and the Mexican Hat wavelet. After the experiments of the abovementioned wavelet functions, the Morlet wavelet was employed in this study. In one dimension, the Morlet wavelet is defined as follows (Kumar and Foufoula-Georgiou, 1997):

$$
\begin{aligned}
\psi(t)= & \pi^{-1 / 4}\left[\exp \left(-i \omega_{0} t\right)-\exp \left(-\omega_{0}^{2} / 2\right)\right] \\
& \exp \left(-t^{2} / 2\right),
\end{aligned}
$$

which is a complex Morlet wavelet. Indeed, the real part of this complex Morlet wavelet is commonly used and its most popular form is:

$$
\psi(t)=\pi^{-1 / 4} \exp \left(-t^{2} / 2\right) \cos \left(\omega_{0} t\right) .
$$

Where $\omega_{0}$ is a non-dimensional constant which allows an exchange between time and frequency resolution, $\omega_{0}=5$ being generally applied. Because of the relatively narrow frequency domain and the relatively wide time domain, the Morlet wavelet can extract fine structures from the time series based on a cluster analysis (Kirby and Swain, 2004). In this study, the real Morlet wavelet (Eq. 9) was applied to obtain the real wavelet coefficient and the result was shown by a contours map of $C(a, \tau)$ along period scale $(a)$ and shift time $(\tau)$.

\section{Results and discussion}

\subsection{Baseflow estimation}

As estimated with the modified Kalinen separation method, the annual mean baseflow in the source region of the Yangtze River is $5.74 \times 10^{9} \mathrm{~m}^{3}$ for the pe- 
riod between 1957 and 2009. In comparison with the inner-annual variation of total streamflow, the baseflow shows a weaker fluctuation. The total flow is completely contributed by baseflow in winter from December to March, but the baseflow contributes $40 \%-70 \%$ of the annual runoff. The inter-annual change of the baseflow exhibits a positive trend after 1980. The variation of annual baseflow can be characterized with coefficient of variation $\left(C_{v}\right)$, a parameter in statistics to indicate the dispersion of time series. Before the $1980 \mathrm{~s}$, it was in a steady state, with a variation coefficient of 24.7; and after then, it demonstrated dramatic variations and large amplitudes, with its variation coefficient being increased to 33.2. The annual baseflow reached a maximum value of $11.29 \times 10^{9}$ $\mathrm{m}^{3}$ in 1989 and a minimum value of $2.86 \times 10^{9} \mathrm{~m}^{3}$ in 1979 (Fig. 2).

In order to capture the long-term behavior of data, annual baseflow was selected for periodical analysis with wavelet method. The results of wavelet coefficients and variance obtained by using real Morlet wavelet function are shown in Fig. 3. It can be found that the pattern of baseflow from 1957 to 2009 is characterized by a long-term trend and two significant periods. The three horizontal dashed lines in Fig. 3 represent the strong trends for the periods of 43 years, 21 years and 7 years, respectively. In this study, the trend for the longest period (43-year) can be considered as the trend of runoff or baseflow. At a scale of series data, the trend can be linear or fluctuating. Thus, it is reasonable to consider the longest 43-year period exhibits a fluctuating trend, the curve of which is smooth and stable.

The annual baseflow displays a long-term regularity, and its wavelet coefficient is at a local peak in around 1957, reaches a trough in around 1983, and then returns to local peak in around 2009. According to the trend, it can be predicted that the next local peak will

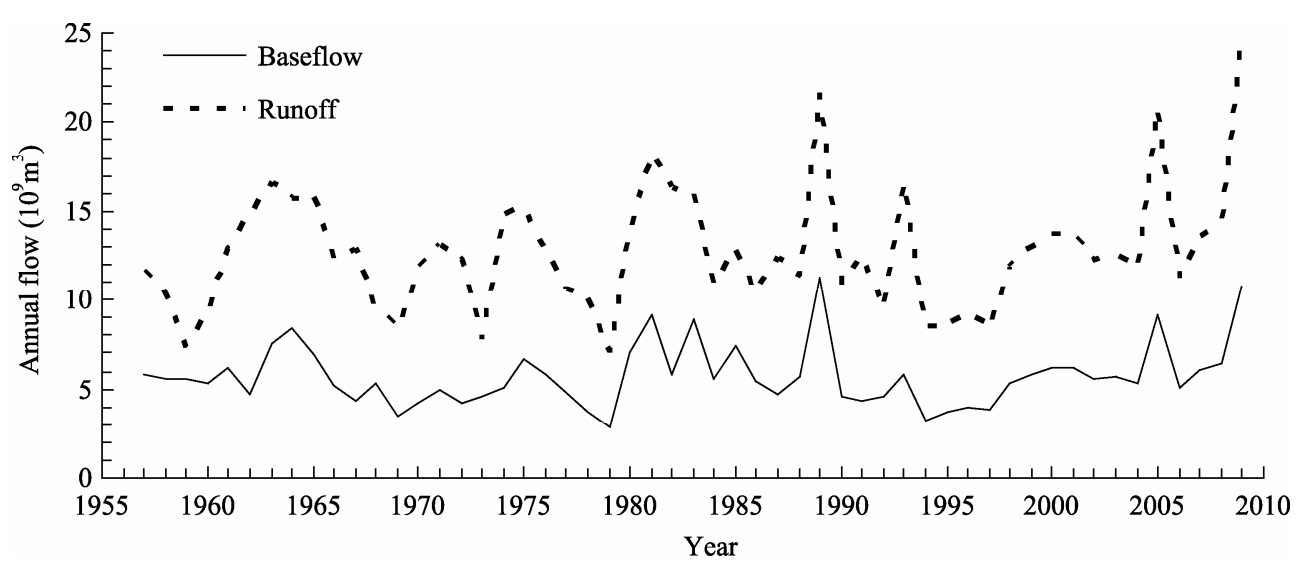

Fig. 2 Changes of annual baseflow and annual runoff in the source region of the Yangtze River

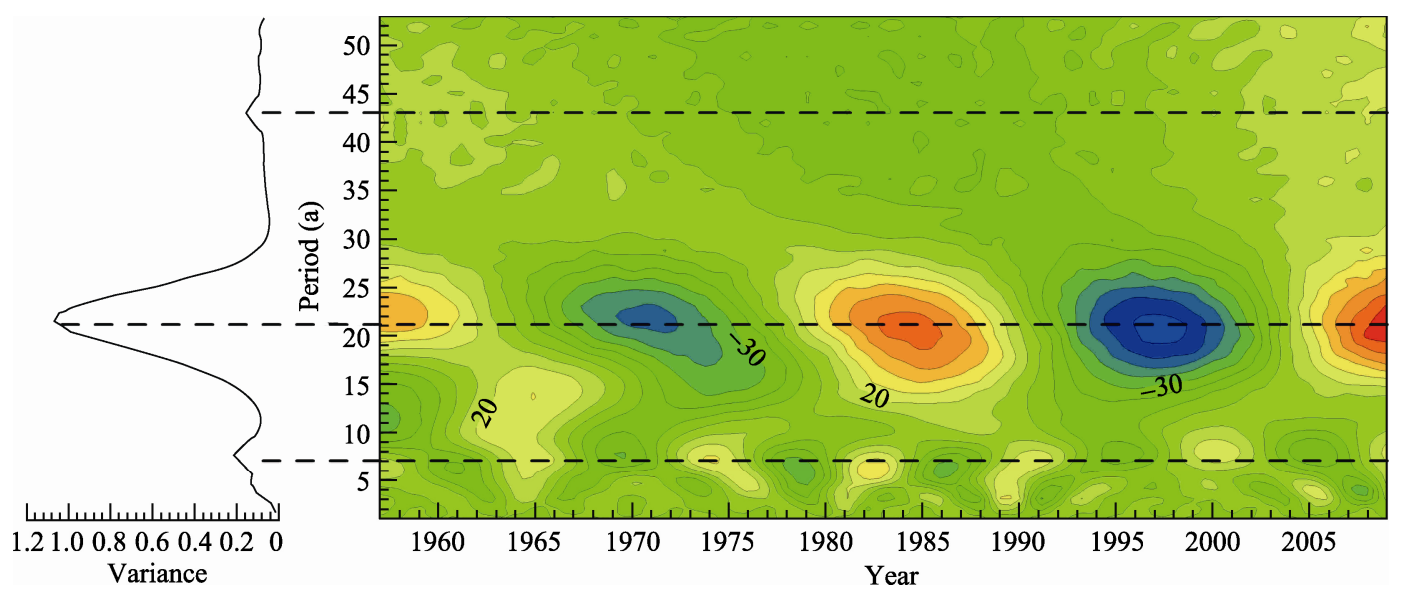

Fig. 3 Wavelet transformation of annual baseflow: contour map of wavelet coefficients and variance for different periods 
appear in 2020. In comparison, the 21-year period turns to local peak in around 2009. According to the trend is significant, which represents strong fluctuations of annual baseflow. Its peak occurred in 1957, 1984 and 2009, respectively, while troughs came into being in 1971 and 1997. Differently, the 7-year period trend reached its peak in 1957, 1965, 1974, 1983,
1990, 2000 and 2009, and troughs emerged in 1961, 1969, 1979, 1986, 1995 and 2005, respectively.

Wavelet coefficients of the 43-year trend and the two significant periods were extracted to show further information, as shown in Fig. 4. It can be seen that the summation of the decomposed wavelet coefficients exhibits a similar pattern to the annual baseflow,
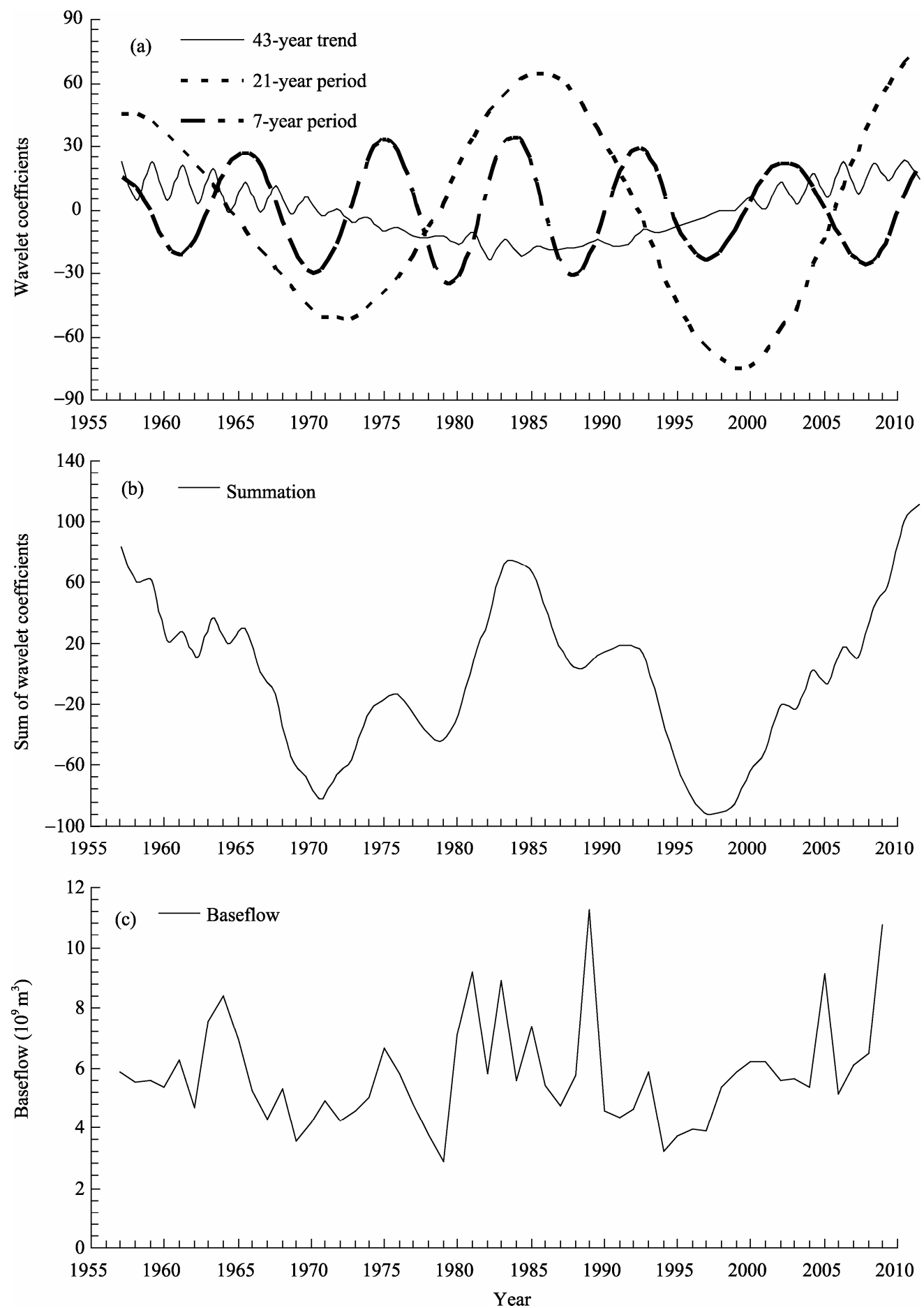

Fig. 4 Similarity between summation (b) of wavelet coefficients for 43-year, 21-year and 7-year periods (a) and baseflow (c) 
which demonstrates the efficiency of Morlet wavelet in capturing the dominative periods of baseflow. Furthermore, the summation curve takes a ' $\mathrm{W}$ ' shape, which means that the baseflow follows the sequence of descending-ascending-descending-ascending.

\subsection{Impacts of precipitation and temperature}

The Morlet wavelet method was applied for precipitation and temperature data analysis, in an aim to probe into the impacts of the two factors on the baseflow in the source region of the Yangtze River. Precipitation and air temperature data for the same period are available at the four meteorological stations. In view of regional hydrological features, the Thiessen Polygon method was used in zone division (Fig. 1) to estimate average precipitation and temperature. The average values of precipitation $\left(P_{\text {avg }}\right)$ and air temperature $\left(T_{\text {avg }}\right)$ were calculated as follow:

$$
\begin{aligned}
P_{\text {avg }}= & 0.48 \times P_{t t h}+0.26 \times P_{q m l}+ \\
& 0.05 \times P_{y s}+0.21 \times P_{w d l}, \\
T_{a v g}= & 0.48 \times T_{t t h}+0.26 \times T_{q m l}+ \\
& 0.05 \times T_{y s}+0.21 \times T_{w d l} .
\end{aligned}
$$

Where the subscripts $t$ th, $q m l, y s$ and $w d l$ represent the names of the meteorological stations, i.e. Tuotuohe, Qumalai, Yushu and Wudaoliang, respectively. After that, the wavelet coefficients of $P_{a v g}$ and $T_{a v g}$ from 1957 to 2009 were obtained by the same method applied in baseflow analysis.

Precipitation acts as the dominative control of baseflow because it is the ultimate source of subsurface runoff. As a result, the annual baseflow is generally proportional to the annual precipitation. In contrast, the impact of air temperature seems more complex and indirect. Air temperature can influence the forms of precipitation, regional evaporation and special hydro-geological conditions, such as the frozen soils in this cold region. It is expected that the Morlet wavelet transformation can reveal how baseflow is affected by these climatic factors in the source region of the Yangtze River. Thus, the relationship between baseflow, precipitation and air temperature was investigated in the time-frequency space with normalized wavelet coefficients.

As shown in Fig. 5, the relationship among baseflow, precipitation and temperature was implied in the correlation between their normalized wavelet coeffi- cients at different temporal scales. Figures 5 (a) and (b) show significant positive linear correlations both between precipitation and baseflow (correlation coefficient is 0.98 ) and between temperature and baseflow (correlation coefficient is 0.90 ) for the 43-year wavelet coefficients. The correlations suggest that the longterm increasing trends of precipitation and air temperature lead to an increasing trend of baseflow. For the wavelet coefficients of 21-year and 7-year periods, the positive linear correlation between precipitation and baseflow is significant, as shown in Figs. 5c and 5e. However, the correlation between air temperature and baseflow is not so evident, especially for the 21-year period (Figs. 5d, 5f).

To make an integrated analysis of the correlation result, the multivariate linear regression method was applied. The summarized wavelet coefficient of baseflow, as shown in Fig. 4b, was assumed to be the linear combination upon normalized wavelet coefficients of precipitation and air temperature. Since the correlation between 21-year coefficients of temperature and baseflow is very weak, the air temperature for the 21-year period was not taken into account. The final result can be expressed as:

$C_{B F}=0.72 P_{43}+2.32 P_{21}+1.06 P_{7}-0.18 T_{43}+0.32 T_{7}$.

Where, $C_{B F}$ is the wavelet coefficient summation of baseflow shown in Fig. $4 \mathrm{~b} ; P_{43}, P_{21}$ and $P_{7}$ represent the normalized wavelet coefficients of precipitation for 43-year, 21-year and 7-year periods, respectively; $T_{43}$ and $T_{7}$ represent normalized wavelet coefficient of temperature for 43-year and 7-year periods, respectively. According to the regression coefficients in Eq. (12), the change of annual baseflow was contributed mostly by the change of precipitation (88.4\%) and secondly by the change of air temperature (11.6\%). To be specific, the contribution ratios of precipitation change for 43-year, 21-year and 7-year periods are $15.5 \%, 50.1 \%$ and $22.8 \%$, respectively, and the contribution ratios of air temperature change for 43-year and 7 -year periods are $3.9 \%$ and $7.7 \%$, respectively.

\section{Conclusions}

With modified Kalinen baseflow separation method, the baseflow in the source region of the Yangtze River was estimated, and the periodical characteristics of baseflow were revealed by real Morlet wavelet meth- 

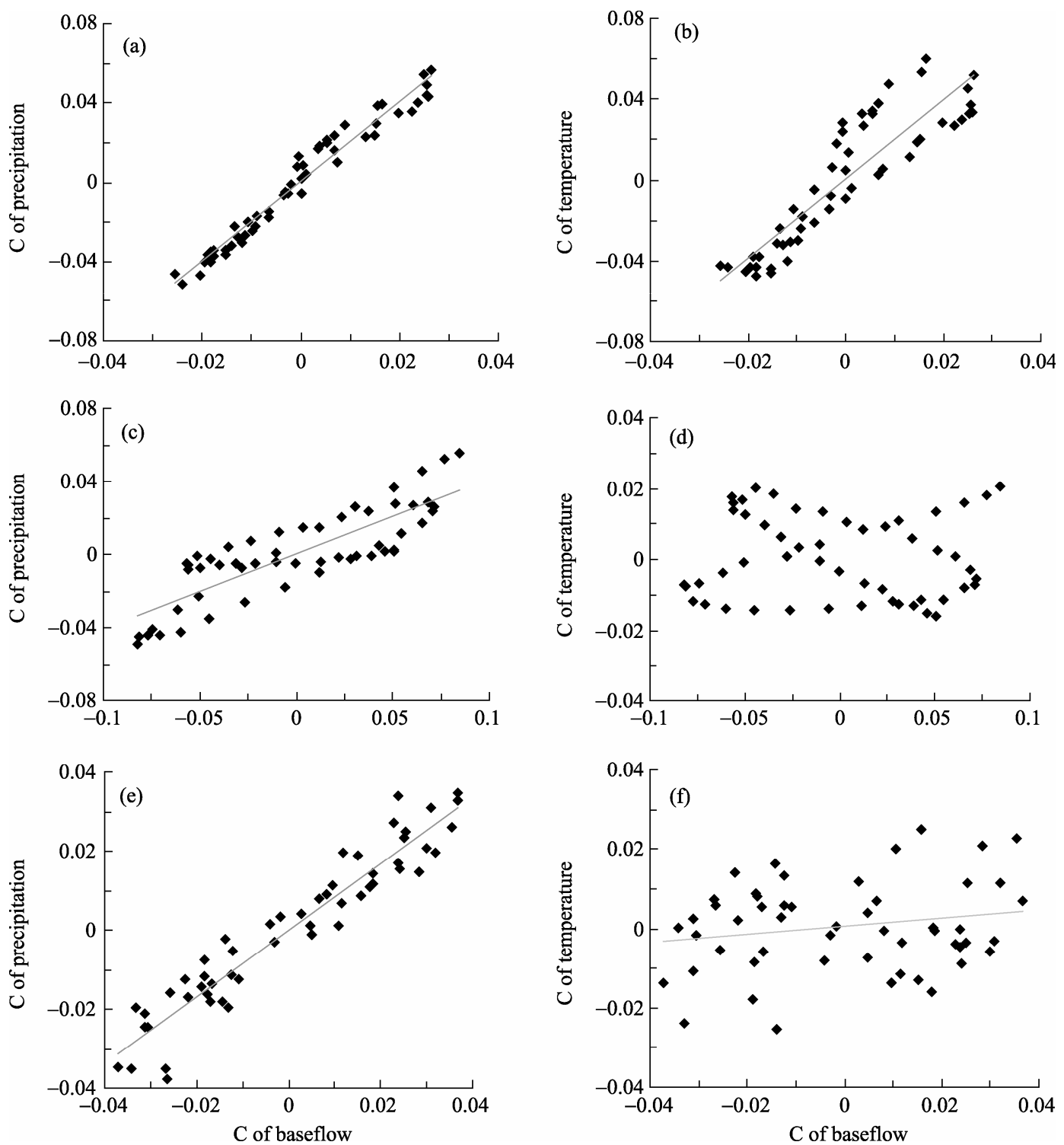

Fig. 5 Correlations of the normalized wavelet coefficient $(C)$ between baseflow and precipitation and air temperature for the periods of 43-year (a, b), 21-year (c, d) and 7-year (e, f)

od. The results show that there are three significant trends existing on 43-year, 21 -year and 7-year periods. The most powerful trend is for the 21-year period. Simple summation of the wavelet coefficients for these three significant periods shows a similar change pattern with respect to the wavelet coefficient of baseflow. It demonstrates that Morlet wavelet is efficient in capturing the dominative periods of hydrological series.

Annual precipitation and annual air temperature were analyzed as well with the real Morlet wavelet method by taking into consideration their impacts on annual baseflow. Their wavelet coefficients are normalized and the results of the typical trends for 43-year, 21-year and 7-year periods were selected for correlation analysis. The result indicates that an approximate linear positive correlation between baseflow and precipitation for all periods exists. However, the correlation between baseflow and air temperature is significantly weak, except for the 43 -year period. A linear regression equation was used to estimate the wavelet coefficient of baseflow based on wavelet coefficients of precipitation and air temperature. The regression coefficients indicate that the change of annual baseflow was contributed mostly by the change of precipitation $(88.4 \%)$ and secondly by the change of temperature $(11.6 \%)$. 


\section{Acknowledgements}

This study was funded by the China Geological Survey (12120 10818093), the National Natural Science Foundation of China

\section{References}

Adamowski J, Sun K. 2010. Development of a coupled wavelet transform and neural network method for flow forecasting of non-perennial rivers in semiarid watersheds. Journal of Hydrology, 390(1-2): 85-91.

Aksoy H, Unal N E, Pektas A O. 2008. Smoothed minima baseflow separation method for perennial and intermittent streams. Hydrology Processes, 22(22): 4467-4476.

Aksoy H, Kurt I, Eris E. 2009. Filtered smoothed minima baseflow separation method. Journal of Hydrology, 372(1-4): 94-101.

Aksoy H, Wittenberg H. 2010. Groundwater intrusion into leaky sewer systems. Water Science and Technology, 62(1): 92-98.

Aksoy H, Wittenberg H. 2011. Nonlinear baseflow recession analysis in watersheds with intermittent streamflows. Hydrology Science Journal, 56(2): 226-237.

Bayazit M, Aksoy H. 2001. Using wavelets for data generation. Journal of Applied Statistics, 28(2): 157-166.

Chen G C, Huang Z W, Lu X F, et al. 2002. Characteristics of wetland and its conservation in the Qinghai Plateau. Journal of Glaciology and Geocryology, 24(3): 254-259.

Chen L Q, Liu C M, Li F D. 2006a. Reviews on base flow researches. Progress in Geography, 25(1): 1-15.

Chen L Q, Liu C M, Hao F H, et al. 2006b. Change of the base-flow and its impacting factors in the source regions of Yellow River. Journal of Glaciology and Geocryology, 28(2): 141-148.

Chen L Q, Liu C M, Yang C. 2006c. Baseflow estimation of the source regions of the Yellow River. Geographical Research, 25(4): 659-665.

Compagnucci R H, Blanco S A, Figliola M A, et al. 2000. Variability in subtropical Andean Argentinean Atuel river: a wavelet approach. Environmetics, 11(3): 251-269.

Coulibaly P, Burn D H. 2004. Wavelet analysis of variability in annual Canadian streamflows. Water Resources Research, 40(3): 1-14.

Grossmann A, Morlet J. 1984. Decomposition of functions into wavelets of constant shape, and related transforms. Journal of Mathematical Analysis and Applications, 15: 723-736.

Guyodo Y, Gaillot P, Channell J E T. 2000. Wavelet analysis of relative geomagnetic paleointensity at ODP Site 983. Earth and Planetary Science Letters, 184(1): 109-123.

Hsu K C, Li S T. 2010. Clustering spatial-temporal precipitation data using wavelet transform and self-organizing map neural network. Advances in Water Resources, 33: 190-200.

Hu H C, Wang G X, Wang Y B, et al. 2009. Response of soil heat-water
(41072191) and Foundation of Graduate Student Science and Technology Innovation from China University of Geosciences in Beijing. The authors wish to acknowledge two anonymous reviewers whose comments have led to a significant improvement of the paper.

processes to vegetation cover on the typical permafrost and seasonally frozen soil in the headwaters of the Yangtze and Yellow rivers. Chinese Science Bulletin, 54(2): 242-250.

Huang G R, Chen Y Q. 2005. Review of some problems about low runoff. Water Resources and Power, 23(4): 61-64.

Jin D L. 1982. International reviews in groundwater analysis methods. Water Resources Research, 2: 54-60.

Kang E S, Cheng G D, Lan Y C, et al. 1999. A model for simulating the response of runoff from the mountainous watersheds of inland river basins in the arid area of northwest China to climatic changes. Science in China: Series D, 29(Supp1.): 52-63.

Kirby J F, Swain C J. 2004. Global and local isostatic coherence from the wavelet transform. Geophysical Research Letters, 31(24): 1-5.

Kisi O. 2010. Wavelet regression model for short-term streamflow forecasting. Journal of Hydrology, 389(3-4): 344-353.

Kumar P, Foufoula-Georgiou E. 1997. Wavelet analysis for geophysical application. Reviews of Geophysics, 35(4): 385-412.

Labat D. 2005. Recent advances in wavelet analyses: Part 1. A review of concepts. Journal of Hydrology, 314(1-4): 275-288.

Labat D, Ronchail J, Guyot J L. 2005. Recent advances in wavelet analyses: Part 2. Amazon, Parana, Orinoco and Congo discharges time scale variability. Journal of Hydrology, 314(1-4): 289-311.

Labat D. 2008. Wavelet analysis of the annual discharge records of the world's largest rivers. Advances in Water Resources, 31(1): $109-117$.

Liang S H, Wan L, Zhang J F, et al. 2007. Periodic regularity of the base flow in the headwater region of the Yellow River and affecting factors in the dry season. Nature Science Progress, 17(9): 1222-1228.

Liang S H, Xu D W, Wan L, et al. 2008. Periodic regularity of the base flow in the headwater region of the Yellow River and affecting factors. Earth Science Frontiers, 15(4): 281-289.

Liang S H, Ge S M, Wan L, et al. 2010. Can climate change cause the Yellow River to dry up. Water Resources Research, 46(W02505): $1-8$.

Liu J L, Yang Z F, Xiao F, et al. 2005. Conformity calculation models on river ecological baseflows. Acta Scientiae Circumstantiae, 25(4): 436-441.

Lu A X, Yao T D, Wang L H, et al. 2005. Study on the fluctuations of typical glaciers and lakes in the Tibetan Plateau using remote sensing. Journal of Glaciology and Geocryology, 27(6): 783-792.

Qian K Z, Lv J J, Chen T, et al. 2011a. A review on base-flow calcula- 
tion and application. Hydrogeology and Engineering Geology, 38(4): $20-31$.

Qian K Z, Lv J J, Pei C Z, et al. 2011b. Calculation and analysis of baseflow of Tongtian River in the source region of Yangtze River. Arid Land Geography, 34(3): 511-517.

Tallaksen L M. 1995. A review of baseflow recession analysis. Journal of Hydrology, 165: 349-370.

Vogel R M, Kroll C N. 1992. Regional geo-hydrologic geomorphic relationships for the estimation of low-flow statistics. Water Resources Research, 28(9): 2451-2458.

Wang G X, Chen G D. 2001. Characteristics of grassland and ecological changes of vegetations in the source regions of Yangtze and Yellow rivers. Journal of Desert Research, 21(2): 101-107.

Wittenberg H. 1999. Baseflow recession and recharge as nonlinear storage processes. Hydrology Processes, 13(5): 715-726.

Wittenberg H, Sivapalan M. 1999. Watershed groundwater balance estimation using streamflow recession analysis and baseflow separa- tion. Journal of Hydrology, 219(1-2): 20-33.

Wittenberg H. 2003. Effect of season and man-made changes on baseflow and flow recession: case studies. Hydrology Processes, 17(11): 2113-2123.

Yang J P, Ding Y J, Chen R S. 2007. Assessment of eco-environmental vulnerability in the source regions of the Yangtze and Yellow rivers. Journal of Desert Research, 27(6): 1012-1017.

Yin F C, Wang Z G, Liang H. 2004. Advances in low flow research.

Advance in Water Science, 15(2): 249-254.

Zhang D S, Gao S Y. 2007. Research progress on sand desertification in Qinghai Plateau. Journal of Desert Research, 27(3): 367-372.

Zhang H C. 1985. The Study of Water Resources in Plains. Shanghai: Academia Press, 122-126.

Zhang Y K, Schilling K E. 2006. Effects of land cover on water table, soil moisture, evapo-transpiration and groundwater recharge: a field observation and analysis. Journal of Hydrology, 319(1-4): 328-338.

\section{Eight new records of birds found in Xinjiang in 2011}

In 2011, eight new records of birds were found in Xinjiang Uygur autonomous region, including Glossy Ibis (Plegadis falcinellus), Japanese Sparrowhawk (Accipiter gularis), White-naped Crane (Grus vipio), Red-rumped Swallow (Hirundo daurica), Bar-tailed Treecreeper (Certhia himalayana), Azure-winged Magpie (Cyanopica cyana), Eastern Crowned Willow Warbler (Phylloscopus coronatus) and Black-faced Bunting (Emberiza spodocephala). Half of them were recorded by bird-watchers and photography lovers.

The appearance of some birds is occasional in West China, such as the Glossy Ibis, which is small in population in China and was first recorded in the border regions of Kashi, indicating that the bird is probably from neighbor countries. It has also been an occasional event for the White-naped Crane, a species under national key protection and originally lives in Northeast China, to appear in western Xinjiang by intermixing among Common Cranes.

Observers, by means of improved field monitoring, are able to collect specimens through telescopes and telephoto cameras. A steady annual increase in the number of bird records can thus be expected. The recording of Bar-tailed Treecreeper (Certhia himalayana), for instance, has been a hard task due to the mystery of the species. Other species exhibit an obvious tendency of inhabitation expansion probably due to their migration route alterations triggered by global climate change.

The invasion of some specific exotic species into Xinjiang is completely related with anthropogenic factors. In recent years, some alien species bought from the market have been set free, contaminating local biological genetic diversity. The strong adaptability of certain species may go so far as to pose a threat on their counterparts native in Central Asia. 